\title{
Association between physiological stress and skin temperature response after a
}

\section{half marathon}

Alejandro Pérez-Guarner ${ }^{1}$; Jose Ignacio Priego-Quesada ${ }^{1,2 *}$; Fran Oficial-Casado ${ }^{2}$; Rosa M $^{\text {a Cibrián Ortiz de Anda }}{ }^{1}$; Felipe P. Carpes ${ }^{2,3}$; Rosario Salvador Palmer ${ }^{1}$

${ }^{1}$ Biophysics and Medical Physics Group, Department of Physiology, University of Valencia, Valencia, Spain.

${ }^{2}$ Research Group in Sports Biomechanics (GIBD), Department of Physical Education and Sports, University of Valencia, Valencia, Spain.

${ }^{3}$ Applied Neuromechanics Research Group, Laboratory of Neuromechanics, Federal University of Pampa, Uruguaiana, Brazil.

* Corresponding author Jose Ignacio Priego Quesada. Ph.D.

Postal address: Department of Physical Education and Sports, Faculty of Physical Activity and Sport Sciences

C/ Gascó Oliag, 3. 46010. Valencia, Spain.

Phone office: +34 963825554

Fax: +34 963864354

e-mail: j.ignacio.priego@uv.es 


\section{Abstract}

Objective: The objective of this study was to determine the association between skin temperature response and the physiological stress after a half marathon. Approach: Seventeen runners were measured $48 \mathrm{~h}$ before, $24 \mathrm{~h}$ before, $24 \mathrm{~h}$ after and $48 \mathrm{~h}$ after completing a half marathon. The measurements on each day of testing included blood markers (creatine kinase [CK] and glutamate oxaloacetate transaminase [GOT]), perception of pain and fatigue (using a visual analogue scale), skin temperature (using infrared thermography), and jump performance (using countermovement jump test). Main results: $\mathrm{CK}(\mathrm{p}<0.001$ and $\mathrm{ES}=2.1)$, GOT ( $\mathrm{p}=0.04$ and $\mathrm{ES}=1.3)$, and perception of fatigue and pain $(\mathrm{p}<0.001$ and $\mathrm{ES}>1.0)$ increased $24 \mathrm{~h}$ after the half marathon, whereas jump performance decreased $(\mathrm{p}<0.01$ and $\mathrm{ES}=0.4)$. No increase of skin temperature was observed in the tests after the competition and no regression model was able to predict physiological stress using skin temperature. Only a bivariate correlation was observed between the $24 \mathrm{~h}$ variation (pre - 24h) of CK and the skin temperature of the posterior upper limb ( $p=0.04$ and $r=0.5$ ), and between the $48 \mathrm{~h}$ variation (pre $-48 \mathrm{~h}$ ) of pain perceived and the skin temperature of the knee $(\mathrm{p}<0.01$ and $r=0.6)$. Significance: In conclusion, follow-up on basal skin temperatures does not seem to be an adequate method to detect physiological stress after a half marathon. In line with the observed results, we recommend caution when interpreting peaks in basal skin temperature in field sports assessments.

Keywords: infrared thermography; thermal image; running; exercise; fatigue; recovery. 


\section{Abbreviations}

$\Delta \mathbf{C K}_{\mathbf{2 4}}$ : creatine kinase difference between measurement $24 \mathrm{~h}$ post half marathon and the measurements $24 \mathrm{~h}$ and $48 \mathrm{~h}$ before half marathon (average of both).

$\mathbf{A C M J}_{24}$ : jump height difference, in the countermovement jump test, between measurement $24 \mathrm{~h}$ post half marathon and the measurement $24 \mathrm{~h}$ before half marathon.

$\Delta$ GOT $_{24}$ : glutamate oxaloacetate transaminase difference between measurement $24 \mathrm{~h}$ post half marathon and the measurements $24 \mathrm{~h}$ and $48 \mathrm{~h}$ before half marathon (average of both).

$\Delta_{\text {overallfatigue }}$ : : difference in perception of overall fatigue between measurement 24 $\mathrm{h}$ post half marathon and the measurements $24 \mathrm{~h}$ and $48 \mathrm{~h}$ before half marathon (average of both).

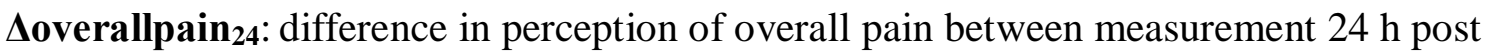
half marathon and the measurements $24 \mathrm{~h}$ and $48 \mathrm{~h}$ before half marathon (average of both).

$\Delta \mathbf{T}_{24}$ : skin temperature difference between measurement 24 h post half marathon and the measurements $24 \mathrm{~h}$ and $48 \mathrm{~h}$ before half marathon (average of both).

CK: creatine kinase.

CMJ: counter Movement Jump test.

ES: effects sizes.

GOT: glutamate oxaloacetate transaminase.

ROI: region of interest.

test-48: test $48 \mathrm{~h}$ before the half marathon competition.

test-24: test $24 \mathrm{~h}$ before the half marathon competition. 
test+24: test $24 \mathrm{~h}$ after the half marathon competition.

test $_{+48}$ : test $48 \mathrm{~h}$ after the half marathon competition.

VAS: visual analogue scale. 


\section{Introduction}

Skin temperature is the result of heat transfer from deep tissues to the skin surface (Ammer and Formenti 2016). When there is no contact with other surface or exposition to convection streams, skin temperature is mainly dependent on skin blood flow, core temperature and environmental temperature being possible to be assessed by infrared thermography (Ammer and Formenti 2016). Measuring skin temperature through infrared thermography to detect injury in professional athletes has been gaining in popularity (Fernández-Cuevas et al 2017). This application is commonly based on the assessment of the thermal symmetry between body sides assuming that asymmetries higher than $0.5-0.7^{\circ} \mathrm{C}$ could be associated with dysfunction of the musculoskeletal system (Fernández-Cuevas et al 2017, Hildebrandt et al 2010, Vardasca et al 2012). Furthermore, the relationship between training load and changes in skin temperature was suggested as another application to investigate (Fernández-Cuevas et al 2014, Priego Quesada and Vardasca 2017).

To identify the relationship between skin temperature response and training response requires observing athletes performing periodic assessments. Hence, a followup analysis of the basal temperatures is necessary to identify changes in thermal characteristics in response to external and internal loads resulting from training and competition. An increase in the load during training or competition can lead to muscle damage and tissue inflammation (Dupuy et al 2018, Silva et al 2018). Such conditions are known to some extent to increase muscle temperature, which may be reflected as changes in skin temperature (Fernández-Cuevas et al 2017, Hildebrandt et al 2010, Ring and Ammer 2012). Skin temperature was also related with skin blood flow 
(Cheuvront et al 2010, Schlager et al 2010), which can be sensitive to exercise intensity (Stöcker et al 2018).

Although the theoretical association between these variables seems simple to explain, available literature lacks evidence on the relationship between physiological stress induced by exercise, and changes in basal skin temperature. Al-Nakhli et al. (2012) reported an increase in the skin temperature of the exercised body region $24 \mathrm{~h}$ after 4 sets of 25 repetitions of bicep concentration curls. In soccer players, two consecutive matches resulted in higher lower limb skin temperature with a weak association ( $\mathrm{r}=0.2-0.4)$ with muscle damage markers (de Andrade Fernandes et al 2017). A recent study found a poor relationship between asymmetry of skin temperature and asymmetry of muscle effort, which may reflect the difficulty involved in correlating skin temperature with training intensity (Trecroci et al 2018).

Here, we set out to determine the association between basal skin temperature response and physiological stress in trained athletes. We assessed the effect of completing a half marathon on different physiological stress markers and on basal skin temperature. Running a half marathon increases levels of oxidative stress, muscle damage, cardiac stress, liver injury markers, and pain perception (Lippi et al 2011, Vassalle et al 2018, Withee et al 2017). We hypothesized that $24 \mathrm{~h}$ and $48 \mathrm{~h}$ after a half marathon, basal skin temperature of the lower limbs would be higher than before competition, and this thermal response would be related to the athlete's level of physiological stress. 


\section{Methods}

\subsection{Participants}

Seventeen recreational runners (6 women and 11 men) with age $41 \pm 6$ years old, body mass $66.5 \pm 10.0 \mathrm{~kg}$, height $1.74 \pm 0.10 \mathrm{~m}$, body fat percentage $14.0 \pm 6.1 \%$, muscular percentage $40.4 \pm 4.5 \%$, body mass index $21.7 \pm 1.5 \mathrm{~kg} / \mathrm{m}^{2}$, and training frequency $5.9 \pm 1.9$ sessions/week participated in the study. Inclusion criteria involved participation in the half marathon competition and a history of running training of at least 4 sessions/week in the past year. Exclusion criteria were the development of any injury or disease during the three months previous to the competition or not finishing the half marathon competition. Necessary data to recruit participants following criteria were obtained using a previous online questionnaire. Three participants were not considered for the criteria of running training frequency and two participants for the injury/disease criteria. To participate in the study, all participants signed a written consent form. This research protocol is in accordance with the Declaration of Helsinki and was approved by the University of Valencia Ethics Committee (approval H1510573609785). In order to reduce skin temperature variability, participants were instructed to avoid smoking, drinking alcohol, caffeine, or other stimulant beverages, large meals, ointments, cosmetics, sunbathing, physiotherapy treatments and high intensity physical activity in the $12 \mathrm{~h}$ before the assessments. The participants confirmed the compliance of each of the instructions on each day of measurement. 


\subsection{Procedures}

In order to assess if a physiological stress after a competition could result in higher skin temperature, we selected a half-marathon competition. The competition was the World Half Marathon Championship in Valencia, Spain, organized by the IAAF on March $24^{\text {th }}$ 2018. Participants performed the half marathon competition in $101.1 \pm 14.1$ min. The experimental design included 4 days of testing performed 48 h before (test-48), $24 \mathrm{~h}$ before (test-24), $24 \mathrm{~h}$ after (test +24 ) and $48 \mathrm{~h}$ after (test +48 ) the participants performed the half marathon. Participants were measured two days before the competition with the aim of both obtaining their normal range of values for several parameters (skin temperature and blood parameters) and training in the procedures (e.g. jump test). Two days after the half marathon, participants were measured in order to determine their physiological responses to the competition. In order to minimize the effects of the circadian rhythm (Marins et al 2015), each participant performed the 4 tests at the same time of day and all measurements were performed in the afternoon (between 3pm and 8pm). The measurements from each day of testing included blood markers, perception of pain and fatigue, skin temperature, and jump performance. Figure 1.A and 1.B depict the experimental design.

\subsection{Blood markers}

Creatine kinase (CK) and glutamate oxaloacetate transaminase (GOT) were measured using a Reflotron ${ }^{\circledR}$ Plus System (F. Hoffman-Roche Ltd., Basel, Switzerland) operated according to the manufacturer's instructions. Both markers were determined from blood samples collected from the finger using reactive strips (Reflotron ${ }^{\circledR}$ CK ref.11126695202 and Reflotron ${ }^{\circledR}$ GOT ref.10745120202). 


\subsection{Fatigue and pain perception}

Perception of fatigue and pain were measured using a 150-mm visual analogue scales (VAS) (Mündermann et al 2002). The scales were labeled from the left as "lowest fatigue/pain imaginable" to the right as "highest fatigue/pain imaginable". Fatigue and pain were measured taking different body sites into consideration: 1) overall, 2) chest and anterior upper limbs, 3) dorsal back and posterior upper limbs, 4) abdominal, 5) lumbar back and buttocks, 6) anterior thigh, 7) posterior thigh, 8) knee and anterior leg and 9) knee and posterior leg.

\subsection{Skin temperature}

Skin temperature was determined using an infrared thermal camera (E-60, 320x240 pixels, Flir Systems Inc., Wilsonville, OR, USA) with noise-equivalent temperature difference (NETD) $<0.05{ }^{\circ} \mathrm{C}$, and measurement uncertainty of $\pm 2{ }^{\circ} \mathrm{C}$ or $2 \%$. Before starting the study, the calibration of the camera was checked using a black body (BX-500 IR Infrared Calibrator, CEM, Shenzhen, China). In order to ensure the quality of the thermography assessment, a TISEM checklist was used to certify that all the important aspects were attended to (Moreira et al 2017) and all the images were taken by the same trained thermography technician (Level I thermographer accredited by the Infrared Training Center). The camera was turned on 10 min before taking the images in order to ensure its stabilization and positioned $1.5 \mathrm{~m}$ from the participant, perpendicular to the body region of interest (ROI). Thermal images were recorded after 10 min of the participant resting so as to adapt to the room temperature (Marins et al 2014), with male 
participants standing up and wearing underpants and women in shorts and sports bras. The room was adequately conditioned for infrared thermography to be used, taking into account the following aspects: area absent of sunlight and airflow; an anti-reflective panel placed behind the participants; only the thermography technician and the participant in the measurement space; and no electronic equipment near the measurement space. Reflected temperature was measured according to the standard method ISO 18434-1:2008 and introduced into the camera setup. Room temperature and relative humidity were input into the camera setup for every thermographic measurement using a thermohygrometer (digital thermohygrometer, TFA Dostmann, Wertheim-Reicholzheim, Germany). Environmental room conditions were $23.2 \pm 0.1^{\circ} \mathrm{C}$ and $20 \pm 1 \%$ of relative humidity (no differences between tests). The maximum environmental outdoor temperatures were $18^{\circ} \mathrm{C}, 22^{\circ} \mathrm{C}, 18^{\circ} \mathrm{C}$ and $18^{\circ} \mathrm{C}$ for the test-48, test-24, test +24 and test +48 , respectively.

The average temperature, the maximum temperature and the standard deviation of 10 ROIs of the full body (Figure 1.C) were obtained using thermography software (Thermacam Researcher Pro 2.10 software, FLIR, Wilsonville, Oregon, USA) and considering an emissivity of 0.98 (Steketee 1973). For the ROIs of the upper and lower limbs, the averages of both sides were considered because no differences were observed between them ( $>0.05)$. In addition, mean skin temperature was calculated using the modified equation of Newburg-Spealman (mean $=0.34 *$ abdomen $+0.15^{*}$ posterior forearm $+0.33^{*}$ posterior thigh $+0.18^{*}$ posterior leg) (Choi et al 1997). 


\subsection{Jump performance}

The Counter Movement Jump test (CMJ) was performed to evaluate the lower limbs power. CMJ performance was recorded using a Chronojump platform (model DIN-A3, Chronojump Bosco-System ${ }^{\circledR}$, Barcelona, Spain). The test-48 was used to familiarize the participants with the CMJ technique. For data collection, participants performed a warm-up consisting of 15-20 squat exercise repetitions and joint mobility. They were instructed to jump as high as possible using the following technique: 1) hold a start position from a standing posture with the hands placed at the hips in order to minimize the influence of arms, 2) to perform a quick semi-squat movement reaching $90^{\circ}$ of knee flexion, and 3) to perform the fastest possible upward movement to jump as high as possible and land on their toes. Participants performed 5 repetitions of the CMJ, with a rest interval of 30 seconds between them (Guglielmo et al 2009). The average of the best 3 highest jumps was used for analyzing jump height (Guglielmo et al 2009).

\subsection{Statistical analysis}

Statistical analysis was performed using the software SPSS 21.0 (IBM Armonk, New York, USA). Data are reported as mean \pm SD with $95 \%$ confidence intervals of the differences between conditions (CI95\%). The normality of the variables was checked using the Shapiro-Wilk test ( $>0.05)$. Repeated measures ANOVA with the test factor time (test- 48 vs. test-24 vs. test +24 vs. test +48 ) were applied for all the variables in order to assess the differences between the measurement days. When significance was found, the Bonferroni post hoc test was applied to identify the differences. The significance level 
was set at 0.05. Cohen's effect sizes (ES) were computed and classified as small (ES 0.2-0.5), moderate (ES 0.5-0.8) or large (ES>0.8) (Cohen 1988).

Different approaches were taken to evaluate the potential of thermal data in estimating the physiological stress of the athletes after competition. Variations in average skin temperature $\left(\Delta \mathrm{T}_{24}, \Delta \mathrm{T}_{48}\right)$ and the other parameters measured (e.g. $\Delta \mathrm{CK}_{24}$, $\Delta \mathrm{GOT}_{24}$, etc.), between pre- (average of test-48 and test-24, although in the case of the CMJ variable only test-24 was considered as the test-48 was considered to be a familiarization test) and post-competition were determined. Then, the correlation between thermal variations and the variations of the other measurements of the study was verified using the Pearson correlation test. Furthermore, an elastic-net penalized linear regression model was used to predict the variables $\mathrm{CK}_{24}$ and $\mathrm{CK}_{48}$ using the thermal variables and several covariates (age, sex, body fat percentage, and training frequency). As the variability of stress suffered by the participants may be masking results, $K$-means cluster analysis was performed to group participants according to their stress level based on the variables that were affected by the half marathon. Student-t tests were used to evaluate the differences between clusters on demographic, physiological and thermal variables. Again, an elastic-net penalized logistic regression model was used to predict the cluster using the thermal variables and the same covariates as the linear model. R-Studio software was used for the elastic-net penalized regressions.

\section{Results}

\subsection{Effects of the half marathon}


Half marathon performance resulted in increased blood markers of CK and GOT in test $_{+24}$ (test $_{-24}$ vs. test +24 : CK CI95\%[291.6, 922.9 U/L] $\mathrm{p}<0.001$ and ES=2.1; GOT CI95\%[1.1, 79.0 U/L] p=0.04 and ES=1.3; Figure 2.A), reduced jump performance (test-24 vs. test +24 : CI95\%[-2.7, $-0.5 \mathrm{~cm}] \mathrm{p}<0.01$ and ES=0.4, Figure 2.C), and higher perception of fatigue and pain in all the body regions (test-24 vs. test +24 , e.g. overall fatigue and pain: fatigue CI95\%[3.0, $6.3 \mathrm{~cm}] \mathrm{p}<0.001$ and $\mathrm{ES}=2.0$; pain CI95\%[1.5, 5.7 $\mathrm{cm}] \mathrm{p}<0.001$ and $\mathrm{ES}=1.7)$. Among all the body regions, higher average ratings of fatigue/pain were found in the lower limbs (Figure 3).

FIGURE 2 NEAR HERE

FIGURE 3 NEAR HERE

Average skin temperature increased in the posterior upper limb and in the anterior leg (test +24 vs. test-48: posterior upper limb CI95\%[0.3, $\left.1.3^{\circ} \mathrm{C}\right] \mathrm{p}<0.001$ and $\mathrm{ES}=0.9$; anterior leg $\mathrm{CI} 95 \%\left[0.2,1.3^{\circ} \mathrm{C}\right] \mathrm{p}<0.01$ and $\mathrm{ES}=1.0$ ) after the half marathon (Figure 4. A). However, average skin temperature increased in the day before the half marathon for most of the ROIs (test-48 vs. test-24: mean skin temperature CI95\%[0.0, $\left.0.9^{\circ} \mathrm{C}\right] \mathrm{p}=0.03$ and $\mathrm{ES}=0.6$; anterior upper $\operatorname{limb} \mathrm{CI} 95 \%\left[0.1,1.1^{\circ} \mathrm{C}\right] \mathrm{p}<0.01$ and $\mathrm{ES}=1.1$;

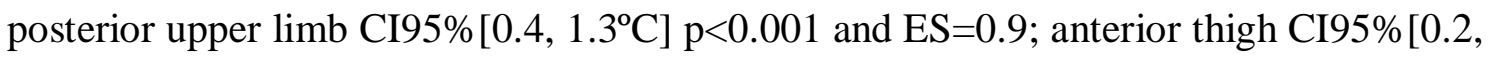
$\left.1.4^{\circ} \mathrm{C}\right] \mathrm{p}<0.01$ and $\mathrm{ES}=0.7$; knee $\mathrm{CI} 95 \%\left[0.5,1.6^{\circ} \mathrm{C}\right] \mathrm{p}<0.001$ and $\mathrm{ES}=0.8$; anterior leg CI95\%[0.5, $\left.1.3^{\circ} \mathrm{C}\right] \mathrm{p}<0.001$ and ES=0.9; posterior leg CI95\%[0.2, $\left.1.1^{\circ} \mathrm{C}\right] \mathrm{p}<0.01$ and ES=0.6). Similar results were observed for maximum skin temperature (Figure 4.B). No differences were observed between the measurement days on the standard deviation of each ROI (Table 1). 
FIGURE 4 NEAR HERE

TABLE 1 NEAR HERE

\subsection{Prediction of physiological stress}

A bivariate correlation analysis showed that the only relationships observed between the skin temperature response and other variables were found for $\Delta \mathrm{CK}_{24}$ and the $\Delta \mathrm{T}_{24}$ of the posterior upper $\operatorname{limb}(\mathrm{p}=0.04$ and $\mathrm{r}=0.5)$, and between $\Delta$ overallpain 48 and the $\Delta \mathrm{T}_{48}$ of the knee $(\mathrm{p}<0.01$ and $\mathrm{r}=0.6)$. No significant linear regression model was obtained to predict the $\Delta \mathrm{CK}_{24}$ or the $\Delta \mathrm{CK}_{48}$ using the skin temperature variations as predictor variables.

For the $k$-means clustering analysis, $\Delta \mathrm{CK}_{24}, \Delta \mathrm{GOT}_{24}, \quad \Delta \mathrm{CMJ}_{24}$, $\Delta$ overallfatigue $_{24}$, and $\Delta$ overallpain $_{24}$ were used as inputs. Subsequently, two clusters were obtained and were denominated as Higher and Lower stress (Table 1). No significant logistic regression model was able to predict the cluster using the $\Delta \mathrm{T}_{24}$ of the different ROIs as predictor variables.

TABLE 2 NEAR HERE

\section{Discussion}


In this study, the aim was to investigate the association between skin temperature and physiological stress variables before and after completing a half marathon competition. Our main findings were that the half marathon resulted in physiological stress, as shown by the increases in different variables (blood markers, jump performance and perception of fatigue and pain). However, physiological stress was not accompanied by basal skin temperature changes. Furthermore, it was not possible to determine a regression model that predicts the stress of the runner using skin temperature variables.

The analysis of all the variables confirmed the presence of stress in response to the competition. Mainly $24 \mathrm{~h}$ after the half marathon there was an increase of CK and GOT markers, reduction in jump performance and increase in the perception of fatigue and pain in all the body regions, especially the lower limbs. These stress effects resultant of the physical effort are in agreement with previous studies (Lippi et al 2011, Rousanoglou et al 2016, Withee et al 2017).

Different approaches were employed to explore the effect of the half marathon on skin temperature, but none of them showed that skin temperature is related with runners' stress: no peak of skin temperature was observed in the tests after the competition and no regression model (linear or logistic) was able to predict the variation in the different measurements of CK or the cluster with higher stress. The possible effect of the half marathon on greater muscle damage and inflammation may be counteracted for by the multifactorial dependence of the skin temperature (FernándezCuevas et al 2015, Priego Quesada et al 2017). In addition, muscle damage and inflammation may not be close to the skin, and therefore not have a significant effect on 
skin temperature. As an example of this, false negatives have been observed in the application of infrared thermography in the detection of breast cancer when the tumour is not superficial and the breast has a low vascularization (Vardasca 2016). Therefore, some studies have used thermal stress protocols (for example, by applying cold), to analyze recovery, which is more influenced by alterations in the deeper tissues (Burkes et al 2016, Fernández-Cuevas et al 2017, Kolacz et al 2017). As observing basal skin temperatures is not enough to provide information about the assimilation of training loads, future studies should analyze whether the application of a thermal stress protocol could provide valuable information about physiological stress, inflammation and postcompetition muscle damage.

In addition to the average skin temperature, we determined other measures for each ROI. The maximum temperature was determined by the maximum value observed within the ROI, which could be more sensitive to changes related to blood flow and inflammation (Ludwig et al 2014, Formenti et al 2018). The main limitation of this variable was that was calculated by a single pixel, and some researchers proposed other estimation from the average of the 125 warmest pixels in the ROI (called Tmax method) which presents less noise (Formenti et al 2018). On the other hand, the standard deviation within the ROI was determined because it represents the temperature distribution within the ROI and could be affected by physical exercise (Ammer and Formenti 2016). These analyses conduced to the same outcomes from average temperature supporting the overall results.

It is important to mention the difference observed between test-48 and test-24 on skin temperature in most of the ROIs. Given that we had provided instructions to the 
participants on reducing their skin temperature variability, one possible explanation of the increase in temperature that occurred in test-24 could be the result of the $4^{\circ} \mathrm{C}$ increase in the environmental temperature of the city recorded on that day. Another possible explanation is the activation of the sympathetic activity of the autonomic nervous system due to the nerves caused on the day before the competition (Formenti and Merla 2017). The differences observed in skin temperature two days before the competition is an important result since it highlights the complexity of practically applying the analysis of athletes' basal temperatures. The interpretation of the results in a sports club is complicated because an increase in the skin temperature could also be due to environmental, psycho-physiological causes or other factors, and not only to the training workloads of the previous sessions.

Some results were observed such as the increase in skin temperature of the posterior upper limb and in the anterior leg compared with $48 \mathrm{~h}$ before the half marathon, correlations observed between $\Delta \mathrm{CK}_{24}$ and the $\Delta \mathrm{T}_{24}$ of the posterior upper limb, and between $\Delta$ overallpain $_{48}$ and the $\Delta \mathrm{T}_{48}$ of the knee, or the differences between cluster on abdominal skin temperature. Some of these results had a logical direction of association and could provide future research directions. Correlation between $\Delta \mathrm{CK}_{24}$ and the $\Delta \mathrm{T}_{24}$ of the posterior upper limb could be interpreted as a result of an increase of skin blood flow on the recovery in a region that it is not affected by muscle damage. In the case of the knee, this region is very susceptible to suffering inflammation after the repetition of impacts over long running distances, which could explain the observed association. However, it is important to be cautious because these results are isolated and may be the result of chance. Future studies should explore whether they can be replicated. 
CK isoenzymes of muscles are more specific for measuring muscle damage than CK in plasma, and this can be considered as a limitation of our study. However, we decided to measure CK in plasma in order to better reproduce the measurements that were performed in the field of application. Another limitation of the study was the low number of women, which did not allow an analysis of sex differences.

\section{Conclusion}

Following up basal temperatures does not seem to be an adequate method to detect the stress produced by a half marathon. Furthermore, skin temperature responses to a half marathon were not able to predict physiological stress markers in runners. In line with the observed results, we recommend caution when interpreting peaks in basal skin temperature in field sports assessments.

\section{Acknowledgments}

FPC acknowledges the support from CNPq-Brazil and Universitat de València (Guest professor program). We would like to thank all the runners for their voluntary participation in this study. This research did not receive any specific grant from funding agencies in the public, commercial, or not-for-profit sectors.

\section{Declarations of interest: none}




\section{References}

Al-Nakhli H H, Petrofsky J S, Laymon M S and Berk L S 2012 The use of thermal infra-red imaging to detect delayed onset muscle soreness J. Vis. Exp. JoVE

Ammer K and Formenti D 2016 Does the type of skin temperature distribution matter? Thermol. Int. 26 51-4

de Andrade Fernandes A, Pimenta E M, Moreira D G, Sillero-Quintana M, Marins J C B, Morandi R F, Kanope T and Garcia E S 2017 Skin temperature changes of under-20 soccer players after two consecutive matches Sport Sci. Health 13 635-643

Burkes S A, Patel M, Adams D M, Hammill A M, Eaton K P, Randall Wickett R and Visscher M O 2016 Infantile hemangioma status by dynamic infrared thermography: A preliminary study Int. J. Dermatol. 55 e522-532

Cheuvront S N, Kenefick R W, Montain S J and Sawka M N 2010 Mechanisms of aerobic performance impairment with heat stress and dehydration J. Appl. Physiol. Bethesda Md 1985109 1989-95

Choi J K, Miki K, Sagawa S and Shiraki K 1997 Evaluation of mean skin temperature formulas by infrared thermography Int. J. Biometeorol. 41 68-75

Cohen J 1988 Statistical Power Analysis for the Behavioral Sciences, Second Edition (Routledge)

Dupuy O, Douzi W, Theurot D, Bosquet L and Dugué B 2018 An Evidence-Based Approach for Choosing Post-exercise Recovery Techniques to Reduce Markers of Muscle Damage, Soreness, Fatigue, and Inflammation: A Systematic Review With Meta-Analysis Front. Physiol. 9 Online: https://www.ncbi.nlm.nih.gov/pmc/articles/PMC5932411/

Fernández-Cuevas I, Bouzas Marins J C, Arnáiz Lastras J, Gómez Carmona P M, Piñonosa Cano S, García-Concepción M Á and Sillero-Quintana M 2015 Classification of factors influencing the use of infrared thermography in humans: A review Infrared Phys. Technol. 71 28-55

Fernández-Cuevas I, Lastras J A, Galindo V E and Carmona P G 2017 Infrared Thermography for the Detection of Injury in Sports Medicine Application of Infrared Thermography in Sports Science Biological and Medical Physics, Biomedical Engineering ed J I Priego Quesada (Cham, Switzerland: Springer International Publishing) pp 81-109 Online: http://link.springer.com/chapter/10.1007/978-3-319-47410-6_4

Fernández-Cuevas I, Sillero-Quintana M, Garcia-Concepcion M A, Serrano J R, Gómez-Carmona P and Marins J B 2014 Monitoring skin thermal response to training with infrared thermography New Stud Athl. 29 57-71 
Formenti D, Ludwig N, Rossi A, Trecroci A, Alberti G, Gargano M, Merla A, Ammer $\mathrm{K}$ and Caumo A 2018 Is the maximum value in the region of interest a reliable indicator of skin temperature? Infrared Phys. Technol. 94 299-304

Formenti D and Merla A 2017 Infrared Thermography: A Possible Role in Psychophysiology of Sport? Application of Infrared Thermography in Sports Science (Springer) pp 211-234

Guglielmo L G A, Greco C C and Denadai B S 2009 Effects of Strength Training on Running Economy Int. J. Sports Med. 30 27-32

Hildebrandt C, Raschner C and Ammer K 2010 An overview of recent application of medical infrared thermography in sports medicine in Austria Sensors 10 47004715

Kolacz S, Moderhak M and Jankau J 2017 New perspective on the in vivo use of cold stress dynamic thermography in integumental reconstruction with the use of skin-muscle flaps J. Surg. Res. 212 68-76

Lippi G, Schena F, Montagnana M, Salvagno G L, Banfi G and Guidi G C 2011 Significant variation of traditional markers of liver injury after a half-marathon run Eur. J. Intern. Med. 22 e36-38

Ludwig N, Formenti D, Gargano M and Alberti G 2014 Skin temperature evaluation by infrared thermography: Comparison of image analysis methods Infrared Phys. Technol. 62 1-6

Marins J C B, Formenti D, Costa C M A, de Andrade Fernandes A and Sillero-Quintana M 2015 Circadian and gender differences in skin temperature in militaries by thermography Infrared Phys. Technol. 71 322-8

Marins J C B, Moreira D G, Cano S P, Quintana M S, Soares D D, Fernandes A de A, Silva F S da, Costa C M A and Amorim P R dos S 2014 Time required to stabilize thermographic images at rest Infrared Phys. Technol. 65 30-5

Moreira D G, Costello J T, Brito C J, Adamczyk J G, Ammer K, Bach A J E, Costa C M A, Eglin C, Fernandes A A, Fernández-Cuevas I, Ferreira J J A, Formenti D, Fournet D, Havenith G, Howell K, Jung A, Kenny G P, Kolosovas-Machuca E S, Maley M J, Merla A, Pascoe D D, Priego Quesada J I, Schwartz R G, Seixas A R D, Selfe J, Vainer B G and Sillero-Quintana M 2017 Thermographic imaging in sports and exercise medicine: A Delphi study and consensus statement on the measurement of human skin temperature J. Therm. Biol. 69 155-62

Mündermann A, Nigg B M, Stefanyshyn D J and Humble R N 2002 Development of a reliable method to assess footwear comfort during running Gait Posture 16 3845

Priego Quesada J I, Kunzler M R and Carpes F P 2017 Methodological Aspects of Infrared Thermography in Human Assessment Application of Infrared Thermography in Sports Science (Cham, Switzerland: Springer International 
Publishing) pp 49-79 Online: http://link.springer.com/chapter/10.1007/978-3319-47410-6_3

Priego Quesada J I and Vardasca R 2017 Issues and Future Developments of Infrared Thermography in Sports Science Application of Infrared Thermography in Sports Science (Cham, Switzerland: Springer International Publishing) pp 297319 Online: http://link.springer.com/chapter/10.1007/978-3-319-47410-6_12

Ring E F J and Ammer K 2012 Infrared thermal imaging in medicine Physiol. Meas. 33 R33-46

Rousanoglou E N, Noutsos K, Pappas A, Bogdanis G, Vagenas G, Bayios I A and Boudolos K D 2016 Alterations of Vertical Jump Mechanics after a HalfMarathon Mountain Running Race J. Sports Sci. Med. 15 277-86

Schlager O, Gschwandtner M E, Herberg K, Frohner T, Schillinger M, Koppensteiner R and Mlekusch W 2010 Correlation of infrared thermography and skin perfusion in Raynaud patients and in healthy controls Microvasc. Res. 80 54-57

Silva J R, Rumpf M C, Hertzog M, Castagna C, Farooq A, Girard O and Hader K 2018 Acute and Residual Soccer Match-Related Fatigue: A Systematic Review and Meta-analysis Sports Med. Auckl. NZ 48 539-83

Steketee J 1973 Spectral emissivity of skin and pericardium Phys. Med. Biol. 18686

Stöcker F, Oldershausen C V, Paternoster F K, Schulz T and Oberhoffer R 2018 Does postexercise modelled capillary blood flow accurately reflect cardiovascular effects by different exercise intensities? Clin. Physiol. Funct. Imaging 38 431-8

Trecroci A, Formenti D, Ludwig N, Gargano M, Bosio A, Rampinini E and Alberti G 2018 Bilateral asymmetry of skin temperature is not related to bilateral asymmetry of crank torque during an incremental cycling exercise to exhaustion PeerJ 6 e4438

Vardasca R 2016 A review on the role of medical thermography in breast cancer imaging Thermol. Int. 26 75-9

Vardasca R, Ring F, Plassmann P and Jones C 2012 Thermal symmetry of the upper and lower extremities in healthy subjects Thermol. Int. 22 53-60

Vassalle C, Masotti S, Lubrano V, Basta G, Prontera C, Cecco P D, Turco S D, Sabatino L and Pingitore A 2018 Traditional and new candidate cardiac biomarkers assessed before, early, and late after half marathon in trained subjects Eur. J. Appl. Physiol. 118 411-7

Withee E D, Tippens K M, Dehen R, Tibbitts D, Hanes D and Zwickey H 2017 Effects of Methylsulfonylmethane (MSM) on exercise-induced oxidative stress, muscle damage, and pain following a half-marathon: a double-blind, randomized, placebo-controlled trial J. Int. Soc. Sports Nutr. 1424 


\section{Figures and captions}

\section{A. Protocol design}

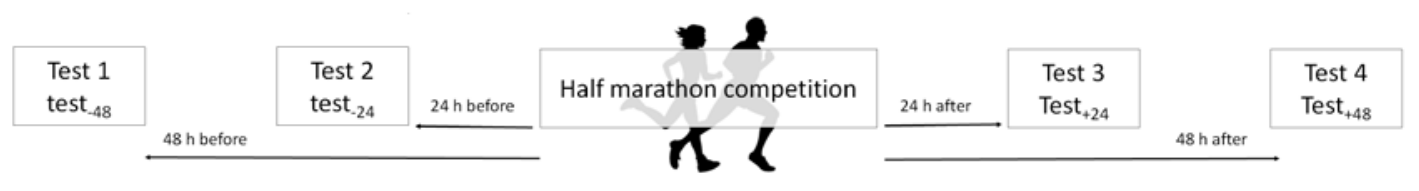

B. Test design

\begin{tabular}{|c|c|c|c|}
\hline Blood markers & $\begin{array}{c}\text { Fatigue and pain } \\
\text { perception }\end{array}$ & $\begin{array}{l}\text { Infrared } \\
\text { thermography }\end{array}$ & CMJ test \\
\hline
\end{tabular}

\section{Regions of Interest}
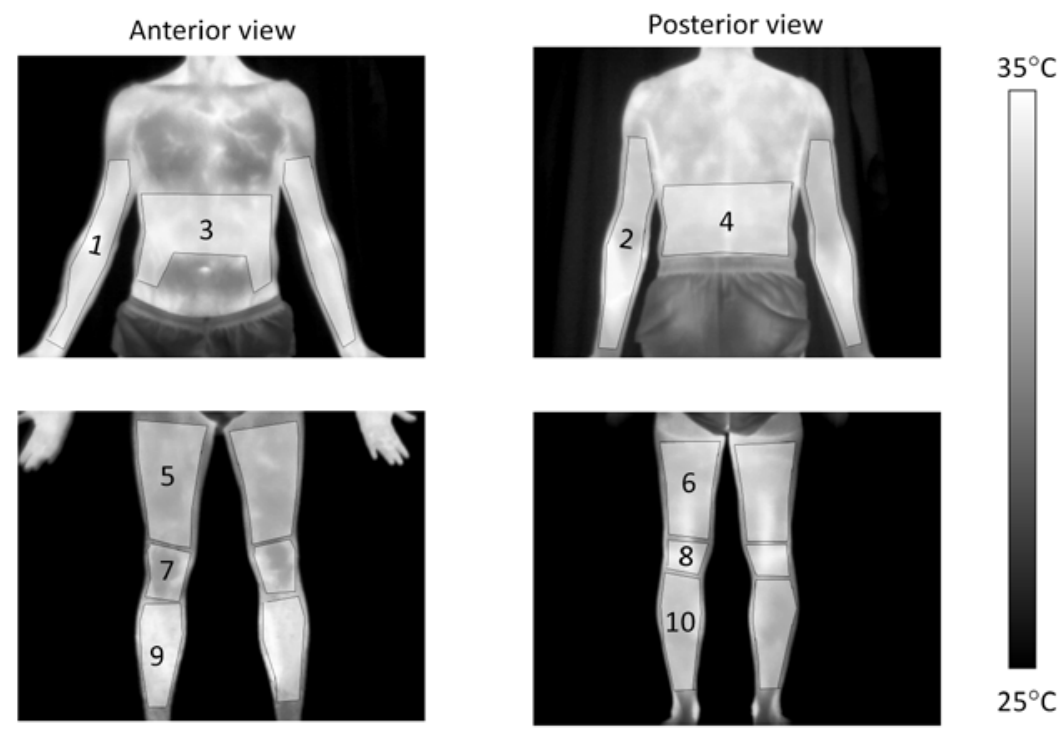

Figure 1. Schematic representation of the experimental design (A), the order in which each test was performed on each day of assessment (B), and the regions of interest for thermography measurements (C): 1) anterior upper limbs, 2) posterior upper limbs, 3) abdominal, 4) lumbar back, 5) anterior thigh, 6) posterior thigh, 7) knee, 8) popliteus, 9) anterior leg, and 10) posterior leg. 


\section{A. Blood markers}

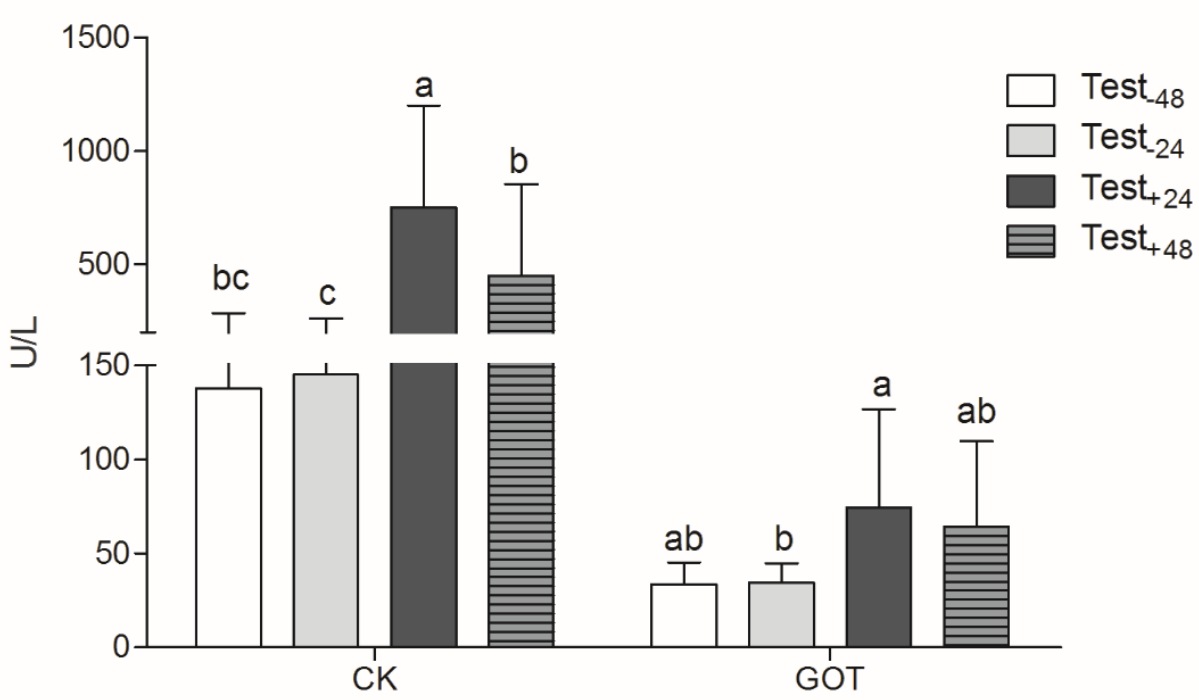

B. CMJ

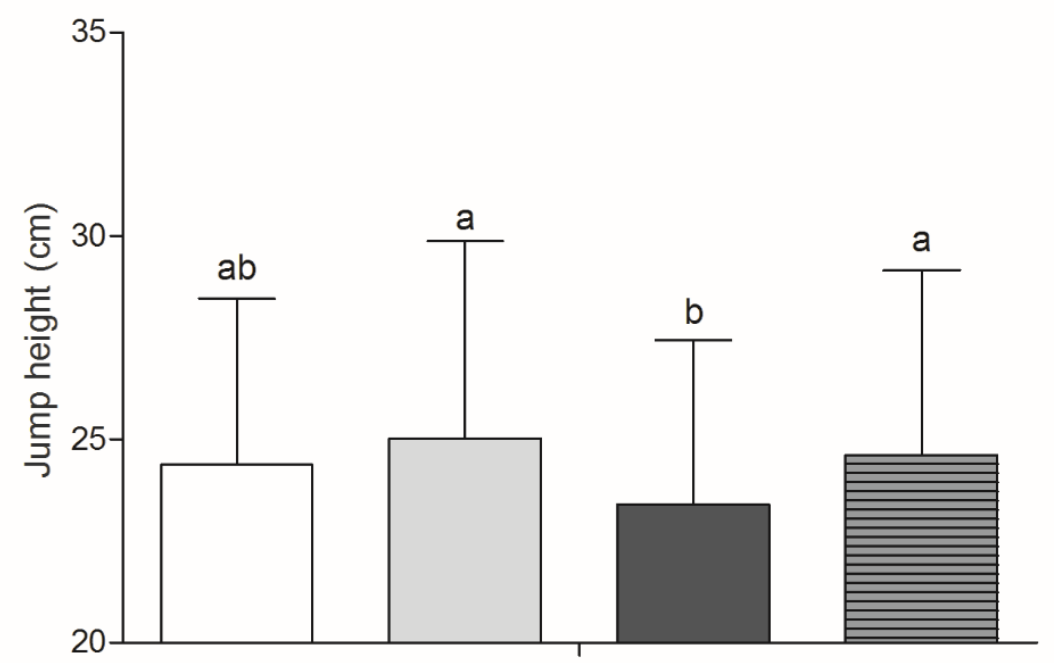

Figure 2. Mean (bars) and standard deviation (vertical lines) of the different measurements of blood markers (A; creatine kinase [CK] and glutamate oxaloacetate transaminase [GOT]), and countermovement jump test (B), $48 \mathrm{~h}$ before (test-48), $24 \mathrm{~h}$ before (test-24), $24 \mathrm{~h}$ after (test +24$)$ and $48 \mathrm{~h}$ after (test +48 ) the half marathon. Different letters identify differences between the measures $(\mathrm{p}<0.05$; alphabetical order was used to reflect the quantity of the values $\mathrm{a}>\mathrm{b}>\mathrm{c}$ ). 


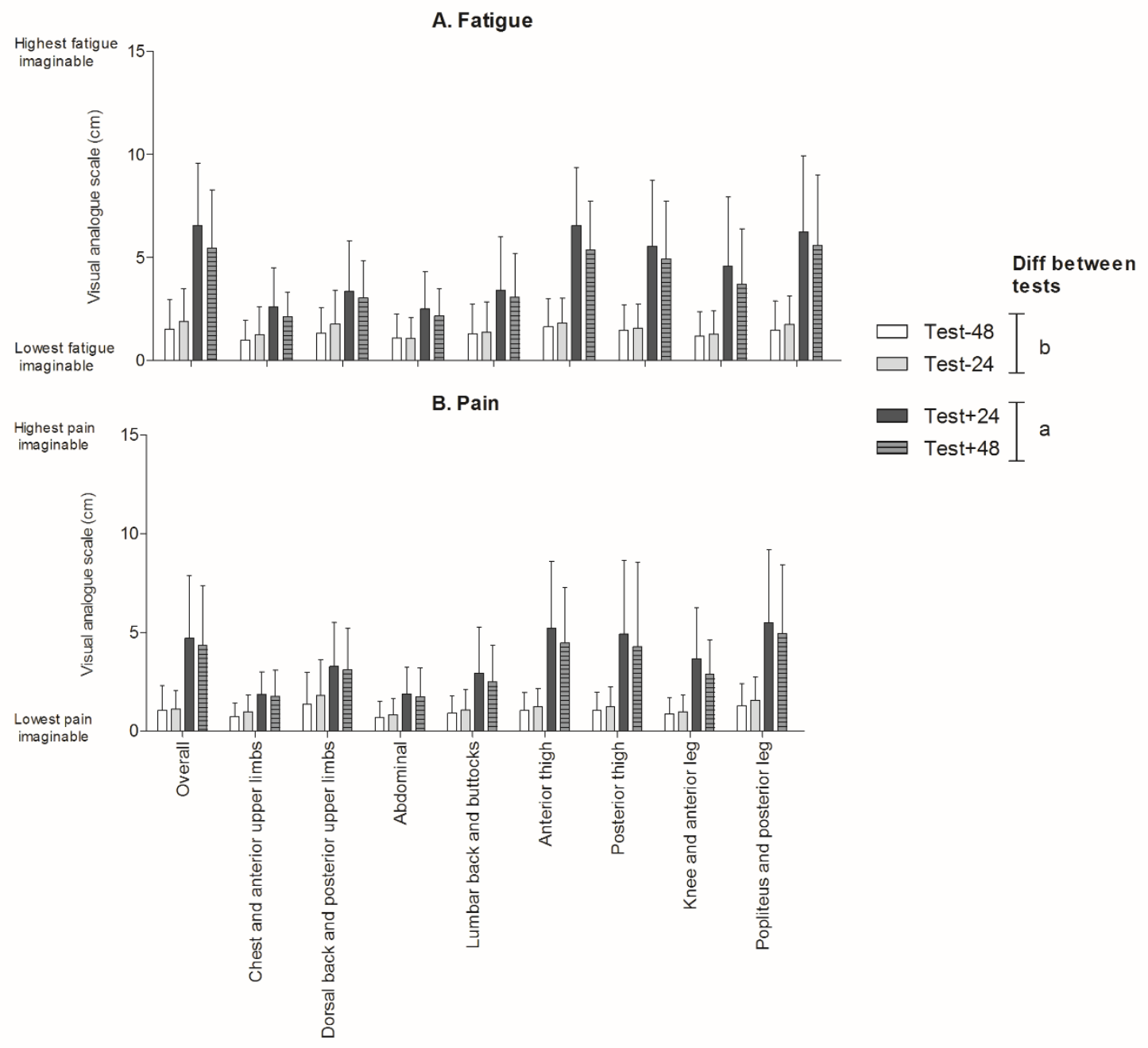

Figure 3. Mean (bars) and standard deviation (vertical lines) of perceived fatigue (A) and pain (B), $48 \mathrm{~h}$ before (test-48), $24 \mathrm{~h}$ before (test-24), $24 \mathrm{~h}$ after (test +24$)$ and $48 \mathrm{~h}$ after $($ test +48$)$ the half marathon. $15 \mathrm{~cm}$ was the highest fatigue/pain imaginable. All the regions of interest presented higher ratings after the marathon than before $(a>b$ at the legend; $\mathrm{p}<0.05)$. 

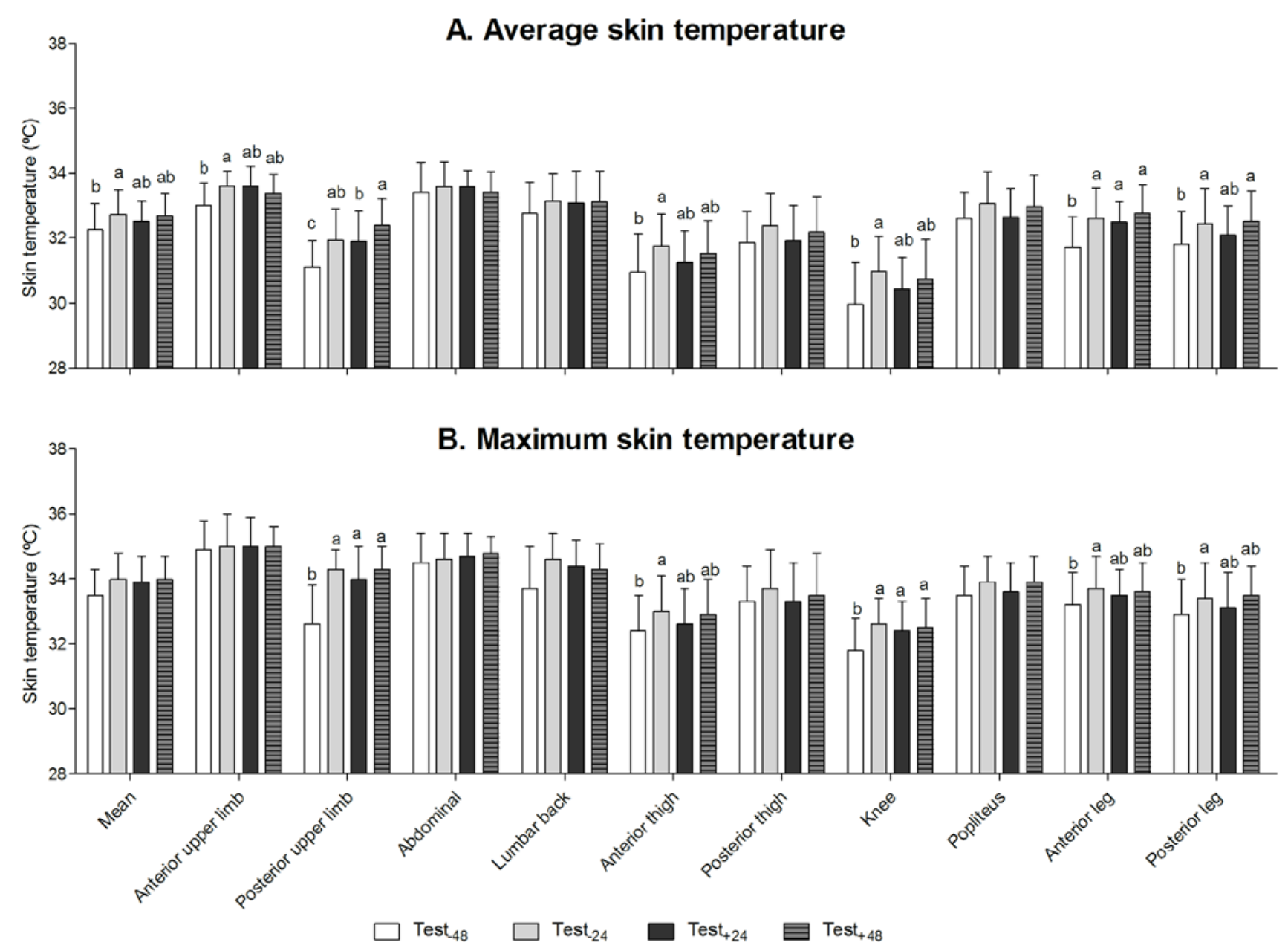
Figure 4. Mean (bars) and standard deviation (vertical lines) of the average (A) and maximum (B) skin temperature measurements, $48 \mathrm{~h}$ before (test-48), $24 \mathrm{~h}$ before (test-24), $24 \mathrm{~h}$ after (test +24$)$ and $48 \mathrm{~h}$ after (test +48 ) the half marathon. Different letters identify differences between the measures $(\mathrm{p}<0.05$; alphabetical order was used to reflect the quantity of the values $\mathrm{a}>\mathrm{b}>\mathrm{c})$. 


\section{Tables}

Table 1. Mean \pm SD of the standard deviation within each region of interest in the four measurement moments: $48 \mathrm{~h}$ before (test-48), $24 \mathrm{~h}$ before (test-24), $24 \mathrm{~h}$ after (test +24$)$ and $48 \mathrm{~h}$ after (test +48 ) the half marathon.

\begin{tabular}{lllll}
\hline Region of interest & Test-48 & Test-24 & Test +24 & Test +48 \\
\hline Anterior upper limb & $0.6 \pm 0.2^{\circ} \mathrm{C}$ & $0.6 \pm 0.1^{\circ} \mathrm{C}$ & $0.6 \pm 0.2^{\circ} \mathrm{C}$ & $0.6 \pm 0.1^{\circ} \mathrm{C}$ \\
\hline Posterior upper limb & $0.9 \pm 0.2^{\circ} \mathrm{C}$ & $0.8 \pm 0.2^{\circ} \mathrm{C}$ & $0.9 \pm 0.2^{\circ} \mathrm{C}$ & $0.8 \pm 0.2^{\circ} \mathrm{C}$ \\
\hline Abdominal & $0.4 \pm 0.1^{\circ} \mathrm{C}$ & $0.4 \pm 0.1^{\circ} \mathrm{C}$ & $0.4 \pm 0.1^{\circ} \mathrm{C}$ & $0.4 \pm 0.1^{\circ} \mathrm{C}$ \\
\hline Lumbar back & $0.6 \pm 0.2^{\circ} \mathrm{C}$ & $0.5 \pm 0.2^{\circ} \mathrm{C}$ & $0.5 \pm 0.2^{\circ} \mathrm{C}$ & $0.5 \pm 0.1^{\circ} \mathrm{C}$ \\
\hline Anterior thigh & $0.5 \pm 0.2^{\circ} \mathrm{C}$ & $0.5 \pm 0.2^{\circ} \mathrm{C}$ & $0.5 \pm 0.2^{\circ} \mathrm{C}$ & $0.5 \pm 0.1^{\circ} \mathrm{C}$ \\
\hline Posterior thigh & $0.6 \pm 0.2^{\circ} \mathrm{C}$ & $0.5 \pm 0.2^{\circ} \mathrm{C}$ & $0.6 \pm 0.2^{\circ} \mathrm{C}$ & $0.5 \pm 0.2^{\circ} \mathrm{C}$ \\
\hline Knee & $0.6 \pm 0.1^{\circ} \mathrm{C}$ & $0.6 \pm 0.1^{\circ} \mathrm{C}$ & $0.7 \pm 0.1^{\circ} \mathrm{C}$ & $0.6 \pm 0.2^{\circ} \mathrm{C}$ \\
\hline Popliteus & $0.5 \pm 0.1^{\circ} \mathrm{C}$ & $0.5 \pm 0.1^{\circ} \mathrm{C}$ & $0.6 \pm 0.2^{\circ} \mathrm{C}$ & $0.5 \pm 0.1^{\circ} \mathrm{C}$ \\
\hline Anterior leg & $0.6 \pm 0.2^{\circ} \mathrm{C}$ & $0.5 \pm 0.1^{\circ} \mathrm{C}$ & $0.6 \pm 0.2^{\circ} \mathrm{C}$ & $0.6 \pm 0.1^{\circ} \mathrm{C}$ \\
\hline Posterior leg & $0.4 \pm 0.1^{\circ} \mathrm{C}$ & $0.4 \pm 0.1^{\circ} \mathrm{C}$ & $0.4 \pm 0.2^{\circ} \mathrm{C}$ & $0.4 \pm 0.1^{\circ} \mathrm{C}$ \\
\hline
\end{tabular}

Note: No differences were observed between measurement days ( $>>0.05)$. 
Table 2. Mean \pm SD of the groups obtained using the $K$-means cluster analysis, denominated as Higher and Lower stress clusters.

\begin{tabular}{|c|c|c|c|c|}
\hline \multirow[t]{2}{*}{ Variables } & \multirow{2}{*}{$\begin{array}{l}\text { Higher stress } \\
\text { Mean } \pm \text { SD }\end{array}$} & \multirow{2}{*}{$\begin{array}{l}\text { Lower stress } \\
\text { Mean } \pm \text { SD }\end{array}$} & \multicolumn{2}{|c|}{ Higher vs. Lower stress } \\
\hline & & & CI95\% & $\mathrm{p}(\mathrm{ES})$ \\
\hline \multicolumn{5}{|l|}{ Participant characteristics } \\
\hline $\mathrm{N}^{\mathrm{o}}$ participants and sex & $\begin{array}{c}3 \text { females } \\
5 \text { males }\end{array}$ & $\begin{array}{c}3 \text { females } \\
6 \text { males }\end{array}$ & --- & ---- \\
\hline Age (years) & $39.6 \pm 7.3$ & $42.8 \pm 3.9$ & $-9.1,2.8$ & $0.28(0.6)$ \\
\hline Body fat (\%) & $15.7 \pm 6.8$ & $13.0 \pm 5.3$ & $-3.5,9.0$ & $0.36(0.5)$ \\
\hline Half marathon time (min) & $104.8 \pm 15.7$ & $97.9 \pm 12.6$ & $-7.8,21.5$ & $0.32(0.5)$ \\
\hline \multicolumn{5}{|l|}{ Cluster's inputs } \\
\hline$\Delta \mathrm{CK}_{24}(\mathrm{U} / \mathrm{L})$ & $1076.6 \pm 178.9$ & $248.6 \pm 59.0$ & $661.5,994.4$ & $<0.001(7.0)$ \\
\hline$\Delta \mathrm{GOT}_{24}(\mathrm{U} / \mathrm{L})$ & $69.7 \pm 69.2$ & $17.7 \pm 18.4$ & $0.7,103.1$ & $0.04(1.2)$ \\
\hline$\Delta \mathrm{CMJ}_{24}(\mathrm{~cm})$ & $-1.1 \pm 1.5$ & $-2.0 \pm 1.6$ & $-0.7,2.5$ & $0.25(0.6)$ \\
\hline$\Delta$ overallfatigue $_{24}(\mathrm{~cm})$ & $4.2 \pm 2.4$ & $5.4 \pm 2.2$ & $-3.5,1.3$ & $0.33(0.6)$ \\
\hline$\Delta$ overallpain $_{24}(\mathrm{~cm})$ & $4.1 \pm 3.0$ & $3.2 \pm 3.2$ & $-2.4,4.1$ & $0.58(0.3)$ \\
\hline \multicolumn{5}{|c|}{ Average skin temperature variations $\left(\Delta \mathrm{T}_{24}\right)\left({ }^{\circ} \mathrm{C}\right)$} \\
\hline Mean & $0.2 \pm 0.5$ & $-0.2 \pm 0.3$ & $-0.0,0.8$ & $0.07(1.0)$ \\
\hline Anterior upper limb & $0.5 \pm 0.7$ & $-0.1 \pm 0.6$ & $-0.1,1.2$ & $0.12(0.8)$ \\
\hline Posterior upper limb & $0.7 \pm 0.6$ & $0.1 \pm 0.5$ & $-0.0,0.27$ & $0.05(1.0)$ \\
\hline Abdominal & $0.4 \pm 0.8$ & $-0.3 \pm 0.5$ & $0.0,1.4$ & $0.04(1.1)$ \\
\hline Lumbar back & $0.3 \pm 1.0$ & $-0.1 \pm 0.4$ & $-0.4,0.4$ & $0.26(0.6)$ \\
\hline
\end{tabular}




\begin{tabular}{lcccc}
\hline Anterior thigh & $-0.3 \pm 1.0$ & $-0.2 \pm 0.5$ & $-0.9,1.0$ & $0.74(0.2)$ \\
\hline Posterior thigh & $-0.2 \pm 0.7$ & $-0.3 \pm 0.5$ & $-0.6,0.3$ & $0.79(0.1)$ \\
\hline Knee & $-0.1 \pm 1.2$ & $-0.1 \pm 0.5$ & $-0.9,1.0$ & $0.96(0.0)$ \\
\hline Popliteus & $-0.2 \pm 0.8$ & $-0.3 \pm 0.4$ & $-0.6,0.3$ & $0.79(0.1)$ \\
\hline Anterior leg & $0.3 \pm 1.0$ & $0.2 \pm 0.3$ & $-0.6,0.9$ & $0.67(0.2)$ \\
\hline Posterior leg & $0.0 \pm 0.8$ & $-0.2 \pm 0.4$ & $-0.4,0.3$ & $0.50(0.4)$ \\
\hline
\end{tabular}

Note: $\Delta_{24}$ for each variable is the difference between measurement $24 \mathrm{~h}$ post half marathon (test +24$)$ and the measurements 24 and $48 \mathrm{~h}$ before half marathon (average of test-48 and test-24; but in the case of $\Delta \mathrm{CMJ}_{24}$ only test-24 was taken into account, given that test-48 was considered

to be a familiarization test). Abbreviations: CK: creatine kinase; GOT: glutamate oxaloacetate transaminase; CMJ: jump height in the countermovement jump test; Overall fatigue: perception of overall fatigue using 15-cm visual analogue scale; Overall pain: perception of overall pain using 15-cm visual analogue scale. 